\title{
Simulation of Neutrons Shielding Properties for Some Medical Materials
}

\author{
Faez WAHEED ${ }^{1, *}$, Meltem Y. IMAMOGLU ${ }^{2}$, Nurdan KARPUZ ${ }^{3}$, Huseyin OVALIOGLU ${ }^{4}$ \\ ${ }^{1}$ Iraqi Radioactive Source Requlatory Authority IRSRA-Iraq \\ * Corresponding Author : Email: faez_radiophysics@yahoo.com - ORCID: 0000-0002-0003-0467 \\ ${ }^{2}$ THK University, Ankara-Turkey

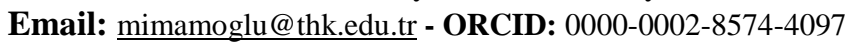

${ }^{3}$ Amasya University, Amasya-Turkey

Email: nurdankarpuz@ amasya.edu.tr - ORCID: 0000-0003-4911-8846

${ }^{4}$ Bursa Uludag University, Bursa-Turkey

Email: ovali@uludag.edu.tr - ORCID: 0000-0002-7224-7526

\section{Article Info:}

DOI: $10.22399 / \mathrm{ijcesen} .1032359$

Received : 04 December 2021

Accepted : 05 January 2022

$\underline{\text { Keywords }}$

Neutron shielding

Medical materials

Radiation protection

\section{Introduction}

The radiation is very important in space technology, nuclear engineering, radiation medicine, radiotherapy, and other fields. On the other hand the radiation requires extreme care due to its hazardous effect to human cell. Thus radiation dosimetry becomes important in science and new techniques, materials have been under study to develop as alternative to conventional materials [1-11].

The neutron with the proton is an important particle in nuclear physics and due to neutral character its shielding is more difficult than others. This is the results of weakly interaction with matter into which it can penetrate deeply. The neutron attenuation is related to the total microscopic neutron cross section $\left(\sigma_{t}\right)$ and the interaction possibility with the material it is given as in equation 1 [12].

$$
\sigma_{t}=\sigma_{s}+\sigma_{a}
$$

where $\sigma_{s}$ is the cross section for both inelastic and elastic scattering.

While comprehensive calculations of radiation attenuation for different materials are available in the literature [13-22], the data for neutron are fairly scarce.

In this study, the fast neutron removal cross section (FNRCS) and related other parameters of $\mathrm{mfp}$, HVL and TVL for water, fat and bone have been calculated.

\section{Materials and Methods}

The FNRCS $\left(\Sigma \mathrm{cm}^{-1}\right)$ and related other parameters have been obtained for four different types of medical interested materials. The chemical properties of

Table 1. Chemical contents of materials (w\%) [23]

\begin{tabular}{|l|l|l|l|l|}
\hline & Water & Fat & Bone & Hydroxyapatite \\
\hline H & 0.1119 & 0.119 & 0.0344 & 0.002 \\
\hline $\mathbf{C}$ & - & 0.772 & 0.714 & - \\
\hline $\mathbf{N}$ & - & - & 0.1827 & \\
\hline $\mathbf{O}$ & 0.8881 & 0.109 & 0.0689 & 0.414 \\
\hline $\mathbf{P}$ & - & - & - & 0.185 \\
\hline Ca & - & - & - & 0.399 \\
\hline
\end{tabular}


materials is listed in table 1 . The simulation was done using Phy-X/PSD online code which is a free online platform [24].

\section{Results and Discussions}

In this study the neutron shielding properties of four different types of materials of medical interested have been obtained. This is done obtaining FNRCS $\left(\Sigma \mathrm{cm}^{-1}\right)$ and some other parameters. The obtained fast neutron removal cross section (FNRCS, $\Sigma \mathrm{cm}^{-1}$ ) results is shown as a function of density of materials in Fig. 1 where it is seen that the FNRCS decreased with the increasing materials' density. As it is well known that hydrogen is important for neutron shielding and this result may be the results of different rate of hydrogen on materials. This was obtained and displayed in Fig. 2. It can clearly be seen that the FNRCS increased with the increasing hydrogen rate in materials. Some other parameters such as $\mathrm{mfp}$, HVL and TVL related to FNRCS are obtained.

The $m f p$ of any material is the neutron penetration length is obtained using equation 2

$$
m f p=\frac{1}{\sum}
$$

The HVL and TVL are expressed as the thickness of materials to stop half (\%50) and $10 \%$ of neutrons and they are obtained using by equation 3 and 4 respectively:

$$
\begin{aligned}
& H V L=\frac{L n(2)}{\Sigma} \\
& T V L=\frac{\operatorname{Ln}(10)}{\Sigma}
\end{aligned}
$$

The obtained results of $m f p, H V L$ and $T V L$ as a function of materials' density is shown in figure 3. It can be seen from this figure that the all quantity have inverse distribution with the FNRCS.

\section{Author Statements:}

- Ethical approval: The conducted research is not related to either human or animal use.

- Conflict of interest: The authors declare that they have no known competing financial interests or personal relationships that could have appeared to influence the work reported in this paper
- Acknowledgement: The authors declare that they have nobody or no-company to acknowledge.

- Author contributions: The authors declare that they have equal right on this paper.

- Funding information: The authors declare that there is no funding to be acknowledged.

- Data availability statement: The data that support the findings of this study are available on request from the corresponding author. The data are not publicly available due to privacy or ethical restrictions.

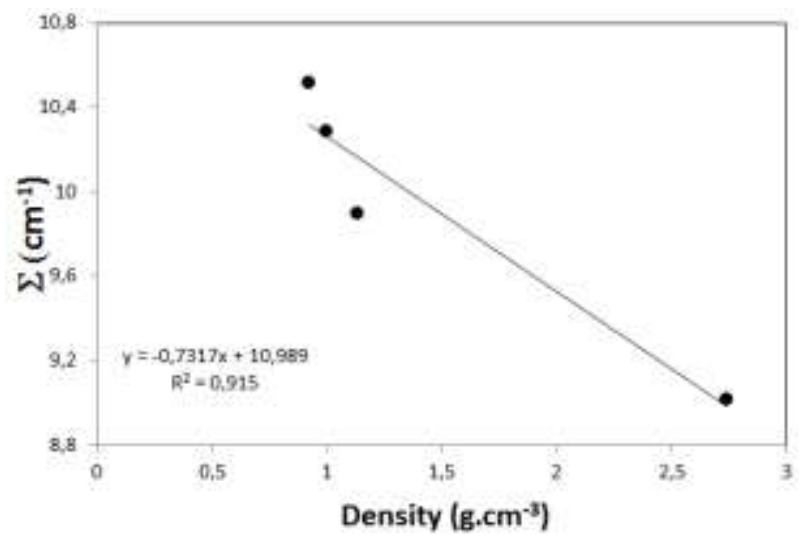

Figure 1. FNRCS as a function of densities of material

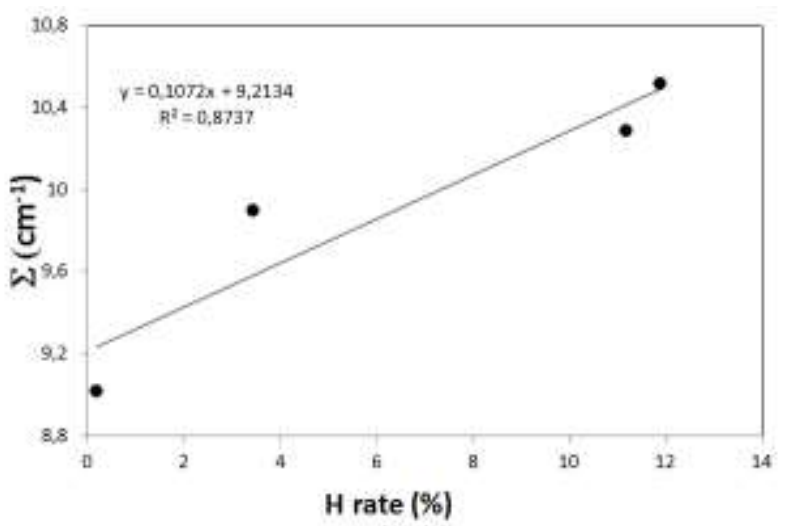

Figure 2. FNRCS as a function of $\mathrm{H}$ rate in materials

\section{References}

[1]Al-Obaidi S., H. Akyıldırım, K. Gunoglu, I. Akkurt (2020). Neutron Shielding Calculation for BariteBoron-Water. Acta Physica Polonica A 137:551553 DOI: 10.12693/APhysPolA.137.551

[2]Roya Boodaghi Malidarrea, Feride Kulali, Aysun Inal, Ali Oz. (2020). Monte Carlo simulation of a waste soda-lime-silica glass system containing $\mathrm{Sb} 2 \mathrm{O} 3$ for gamma-ray shielding. Emerging Materials Research. 9(4):1334-1340. DOI: 10.1680/jemmr.20.00202

[3]Yasser Saad Rammah, Ashok Kumar, Karem AbdelAzeem Mahmoud, Raouf El-Mallawany, Fouad 
Ismail El-Agawany, Gulfem Susoy, et al.. (2020). Emerging materials research 9(3):1000-1008. DOI: $10.1680 /$ jemmr.20.00150

[4]Iskender Akkurt, (2009). Effective atomic and electron numbers of some steels at different energies. Annals of Nuclear. Energy. 36(1112)1702-1705. DOI:10.1016/j.anucene.2009.09.005

[5] M.Y. Hanfi, M.I. Sayyed, E. Lacomme et al., (2021). The influence of $\mathrm{MgO}$ on the radiation protection and mechanical properties of tellurite glasses. Nuclear Engineering and Technology._53(6)20002010 DOI: $10.1016 /$ j.net.2020.12.012
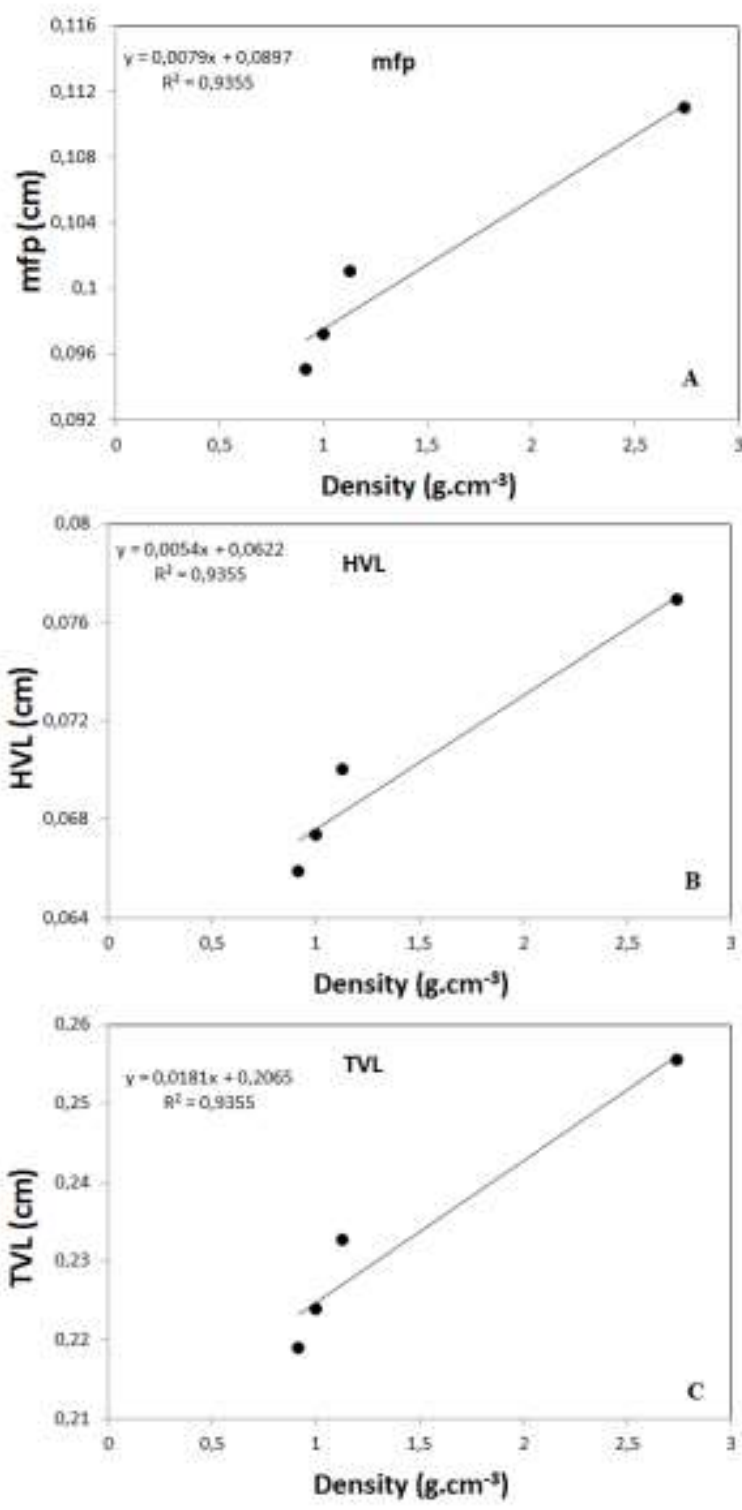

Figure 3. mfp (in upper), HVL (in middle) and TVL (in lower) as a function of density for four types materials

[6]Çelen, Y.Y., Akkurt, İ. \& Kayıran, H.F. (2021). Gamma ray shielding parameters of barium tetra titanate (BaTi4O9) ceramic. J Mater Sci: Mater Electron. 32: 18351-18362. DOI: 10.1007/s10854021-06376-6
[7]Huseyin Ozan Tekin, Baris CAVLI, Elif Ebru ALTUNSOY, Tugba MANICI, Ceren OZTURK, Hakki Muammer KARAKAS (2018). An Investigation on Radiation Protection and Shielding Properties of 16 Slice Computed Tomography (CT) Facilities. International Journal of Computational and Experimental Science and Engineering 4(2):37-40. DOI: 10.22399/ijcesen.408231

[8]Yonca Yahşi Çelen, Atilla Evcin. (2020). No AccessSynthesis and characterizations of magnetite-borogypsum for radiation shielding. Emerging Materials Research 9(3):770-775 DOI: 10.1680/jemmr.20.00098

[9]Boodaghi Malidarre, R., Akkurt, I. (2021). Monte Carlo simulation study on $\mathrm{TeO} 2-\mathrm{Bi} 2 \mathrm{O}-\mathrm{PbO}$ $\mathrm{MgO}-\mathrm{B} 2 \mathrm{O} 3$ glass for neutron-gamma $252 \mathrm{Cf}$ source. J Mater Sci: Mater Electron 32:1166611682 DOI: 10.1007/s10854-021-05776-y

[10]Fouad Ismail, El-Agawany, Karem Abdel-Azeem Mahmoud, Hakan Akyildirim, El-Sayed Yousef, Huseyin Ozan Tekin et al. (2021). Physical, neutron, and gamma-rays shielding parameters for $\mathrm{Na} 2 \mathrm{O}-\mathrm{SiO} 2-\mathrm{PbO}$ glasses. Emerging Materials Research 10(2):227-237 DOI: 10.1680/jemmr.20.00297

[11]H.O. Tekin, Shams A.M. Issa, K.A. Mahmoud, F.I. El-Agawany,Y.S. Rammah, G. Susoy et al. (2020). Nuclear radiation shielding competences of Barium (Ba) reinforced borosilicate glasses. Emerging Materials Research 9(4):1131-1144 DOI: 10.1680/jemmr.20.00185

[12]Woods, J. (1982). Computational Methods in Reactor Shielding, Pergamon Press Inc., New York.

[13] Iskender AKKURT, Huseyin Ozan TEKIN (2020). No AccessRadiological parameters of bismuth oxide glasses using the Phy-X/PSD software Emerging Materials Research 9(3):1020-1027 DOI: 10.1680/jemmr.20.00209

[14]Yonca Yahşi Çelen. (2021). Gamma Ray Shielding Parameters of Some Phantom Fabrication Materials for Medical Dosimetry. Emerging Materials Research 10(3):307-313 DOI: 10.1680/jemmr.21.00043

[15]Yonca Yahsi Çelen, Iskender Akkurt, Yusuf Ceylan, Hasan Atçeken. (2021). Application of experiment and simulation to estimate radiation shielding capacity of various rocks. Arab. J. Geo Sci. 14:1471 DOI: $10.1007 / \mathrm{s} 12517-021-08000-7$

[16]Şen Baykal, D , Tekin, H, Çakırlı Mutlu, R . (2021). An Investigation on Radiation Shielding Properties of Borosilicate Glass Systems . International Journal of Computational and Experimental Science and Engineering, 7(2):99-108 . DOI: 10.22399/ijcesen.960151

[17]O. Günay, M. Sarihan, O. Yarar, İ. Akkurt, M. Demir. (2020). Measurement of Radiation Dose in Thyroid Scintigraphy. Acta Physica Polonica A 137:569 DOI: 10.12693/APhysPolA.137.569

[18] Iskender Akkurt, Roya Boodaghi Malidarre (2022). Physical, structural, and mechanical properties of the concrete by FLUKA code and Phy-X/PSD software. Radiation Physics and 
Chemistry

193:109958.

DOI:10.1016/j.radphyschem.2021.109958

[19]Feride Kulali. (2020). Simulation studies on the radiological parameters of marble concrete. Emerging Materials Research. 9(4):1341-1347. DOI: $10.1680 /$ jemmr.20.00307

[20]I. Akkurt, R.B. Malidarre, I. Kartal, K. Gunoglu. (2021). Monte Carlo simulations study on gamma ray-neutron shielding characteristics for vinyl ester composites Polymer Composites 42:4764-4774. DOI: $10.1002 / \mathrm{pc} .26185$

[21]A.M.El-Khayatt, İ.Akkurt (2013). Photon interaction, energy absorption and neutron removal cross section of concrete including marble. Annals of Nuclear Energy. 60:8-14. DOI: 10.1016/j.anucene.2013.04.021

[22]Aljawhara H. Almuqrin, M.I. Sayyed, Ashok Kumar, B.O. El-bashir, I. Akkurt. (2021). Optical, mechanical properties and gamma ray shielding behavior of $\mathrm{TeO} 2-\mathrm{Bi} 2 \mathrm{O} 3-\mathrm{PbO}-\mathrm{MgO}-\mathrm{B} 2 \mathrm{O} 3$ glasses using FLUKA simulation code . Optical Materials 113:110900 DOI: $10.1016 /$ j.optmat.2021.110900

[23]G. Paternò, P. Cardarelli, A. Contilloa, M. Gambaccini, A. Taibia. (2018). Geant4 implementation of inter-atomic interference effect in small-angle coherent X-ray scattering for materials of medical interest. Physica Medica 51:64-70 DOI: 10.1016/j.ejmp.2018.04.395

[24]Erdem Şakar, Özgür Fırat Özpolat, Bünyamin Alım, M.I. Sayyed, Murat Kurudirek. (2020). Phy-X / PSD: Development of a user friendly online software for calculation of parameters relevant to radiation shielding and dosimetry. Radiation Physics and Chemistry 166:108496 DOI: 10.1016/j.radphyschem.2019.108496 